\title{
Lithium-Ion Battery Management System: A Lifecycle Evaluation Model for the Use in the Development of Electric Vehicles
}

\author{
Ayush Sisodia $^{1}$ and Jonathan Monteiro ${ }^{1 *}$ \\ ${ }^{1}$ Manipal Institute of Technology, Manipal Academy of Higher Education, Manipal, Karnataka, India
}

\begin{abstract}
The use of Lithium-ion batteries in the automobile sector has expanded drastically in the recent years. The foreseen increment of lithium to power electric and hybrid electric vehicles has provoked specialists to analyze the long term credibility of lithium as a transportation asset. To give a better picture of future accessibility, this paper exhibits a life cycle model for the key procedures and materials associated with the electric vehicle lithium-ion battery life cycle, on a worldwide scale. This model tracks the flow of lithium and energy sources from extraction, to generation, to on road utilization, and the role of reusing and scrapping. This life cycle evaluation model is the initial phase in building up an examination model for the lithium ion battery production that would enable the policymakers to survey the future importance of lithium battery recycling, and when in time setting up a reusing foundation be made necessary.
\end{abstract}

Keywords: Lithium-Ion, Batteries, GREET, Electric Vehicles, Hybrid

\section{Introduction}

In the recent age, in comparison to nickel cadmium and lead acid batteries, Li-ion batteries are more suited for electric vehicles since Li-ion batteries have higher energy density, weighs less, brings down the maintenance, and have an extended battery life. [1] Other options, for example, nickel-metal hydride and sodium nickel chloride batteries, confront similar issues as lead acid and nickel cadmium batteries which have lower energy density, power, and execution. Besides, the alternative nickel batteries may likewise have a more critical effect on nature, giving a disincentive for future improvement. Then again, Lithium particle batteries give a superior option as far as energy density, costs, and ecological effect are concerned and are probably going to be a cutting edge of new innovation. [1] Therefore lead-acid and nickel-cadmium batteries are being eliminated and Li-particle batteries are catching an expanding market of the overall industry for electric vehicles.

Li-ion batteries have taken over, particularly in the latest generation of plug-in electric vehicles (PEVs). Worldwide revenue from Li-ion batteries for EVs was less than $\$ 6$ billion in 2014 but is expected to grow to $\$ 26.1$ billion in 2023. [2] This expansion in demand is exceptionally reliant on the stores and resources of lithium. Conservative resource estimates

\footnotetext{
*Corresponding author: jonathan.m@manipal.edu
} 
of $\sim 11$ million tons and there is sufficient ability to fulfill demand until 2050 without actualizing a recycling foundation. [3] In this manner, it is important to not just evaluate the sufficiency of future demand and supply of lithium, but also to consider whether Li-ion batteries can economically control the future of electric vehicles.

For an effective new innovation to endure into the future, it is essential to assess the reserve quantity, lifecycle financial aspects, and potential security issues related with the resource. The initial phase in evaluating the innovation is to build up an entire framework in which the innovation and assets dwell. In a resource constrained world, particularly when resources are not uniformly geologically distributed, it is vital to have the capacity to survey how the potential accessibility of scarce input resources will affect the term suitability of the technology. For any constrained resource, recycling applications may release pressure on natural environment and enhance the financial aspect of the technology that uses the resource. In this manner, an exhaustive comprehensive understanding of the system in which the resource and technology dwell is important to set up resource security, evaluate the advantages of resource reusing, and survey future practicality of the innovation.

\section{Currently Available Concept}

The battery framework relies upon the different necessities of the vehicle, unique to its size, make, and model. Vehicles ought to introduce a suitable battery size and structure to guarantee their security, lifetime, and performance. Li-ion batteries ideally make up $25 \%$ (by weight) of the vehicle and are equipped with a variety of safety features. The lifetime of these batteries relies upon their performance. Better performance guarantees longer battery life, which is important to both consumers and producers.

Battery execution is administered by two critical components: energy, which for the most part manages the driving extent or range, and power, which is revealed at top speed and acceleration. There is generally a tradeoff between range and performance. Batteries can either have higher energy or higher power, however not both. [5] For instance, batteries in an all-Electric Vehicle (EV) are mostly energy based to guarantee a longer driving range; though, batteries in a Hybrid Electric vehicle (HEV) are power-based for performance, given their capacity to completely charge while driving. Plug in Hybrid Electric vehicle (PHEV) batteries utilize a blend that is both vitality and power based. For shorter driving excursions, they are energy based and when battery is completely drained, they are power based.

Battery condition is another critical basis that guarantees battery's optimum usefulness and is for the most part measured as a State of Charge (SOC). The SOC is expressed as a percent of "maximum battery limit." [5] There are two working modes related with SOC: Charge Depleting (CD), in which the vehicle activity is proceeding to decrease in the battery charge, and Charge Sustaining (CS), which holds a moderately steady charge in the battery for every mode of vehicle. [6] The condition of charge of batteries fluctuates crosswise over various utilizations of EV, HEV, and PHEV. EVs generally keep running in CD mode, HEVs run in CD mode, and PHEVs keep running in both CS and CD mode.

Batteries are the governing part of the vehicle where their selection, size, outline, transfer, and reusing affect the quality, lifetime, and security of the vehicle. [1] 
Table 1. Performance Characteristics of Li-ion Batteries in EV, HEV, and PHEV [7]

\begin{tabular}{|c|c|c|c|}
\hline Parameter & EV & HEV & PHEV \\
\hline Technology & $\begin{array}{c}\text { Energy-based due to } \\
\text { longer driving range }\end{array}$ & $\begin{array}{c}\text { Power-based because } \\
\text { batteries do not fully } \\
\text { charge while driving }\end{array}$ & $\begin{array}{c}\text { Energy-based for } \\
\text { shorter driving trips. } \\
\text { Power based upon } \\
\text { battery depletion }\end{array}$ \\
\hline State of Charge & $\mathrm{CD}$ & $\mathrm{CD}$ & CD \& CS at 25\% SOC \\
\hline Energy/Power & 2 & $15-20$ & $3-15$ \\
\hline Battery Dimensions & $>$ HEV \& >PHEV & $1-2 \mathrm{kWh}$ & $5-15 \mathrm{kWh}$ \\
\hline
\end{tabular}

Table 1 summarizes the performances of different types of Electric vehicles. Because of expanding greenhouse emanations and developing risk to resource security at present powering the transportation sector, there is an extreme weight on automakers to devise a new technology that can fulfill the changing needs of the economy. [8]

The improvement of Li-ion batteries utilized in electric and hybrid vehicles are the consequence of that new progression in the economy. The battery is a basic and a significant part of the electric vehicle. The better the battery plays out, the more noteworthy the utility inferred by the two buyers and makers. Different battery chemistries serve one of a kind needs to make and model the vehicle. However, a common factor over all battery technologies is the need to guarantee the long term security of the materials utilized as a part of a battery. That is, there should be sufficient material to meet the present and future requests of the market. Li-ion batteries represent some vulnerability as for the accessibility of $\mathrm{Li}$ as a resource. At last, the lifecycle evaluation model will turn out to be a valuable device to decide the measure of $\mathrm{Li}$ we need and how $\mathrm{Li}$ will be utilized as a resource.

A Lithium work flow model was created after compiling the inventory network of Lithium. The process flow is divided into five sections as shown in Figure 1: Mining/Extraction, Battery production and Assembly, Vehicle Manufacturing, Consumers, and End of Life. Each section details the lithium inflows and outflows throughout the individual stage.

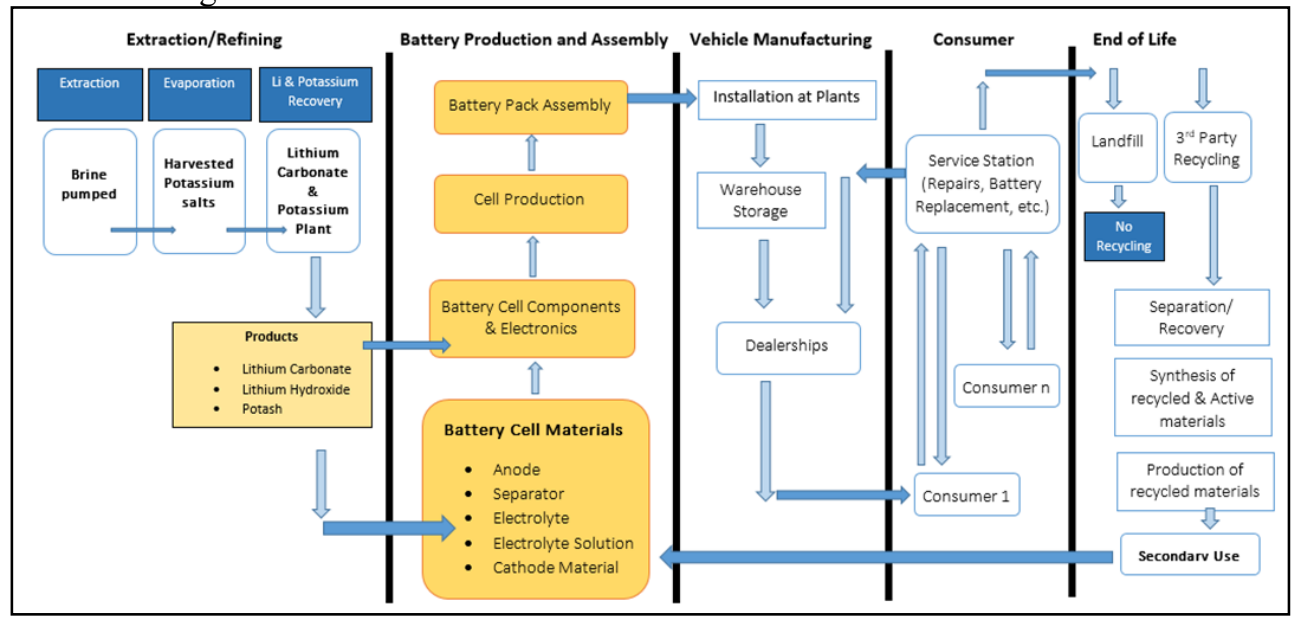

Fig. 1. Lithium Work Flow Model 


\section{Proposed concept and outcome expected}

Once the inventory network for lithium has been investigated and a work flow model has been characterized, the next step is the production of a lifecycle evaluation model. This section plots the methods for making a spreadsheet display, wherein every component of the lithium work flow model is characterized inside a progression of worksheet 'modules.' Every worksheet will take client inputs, for example, amount of metal mined, kind of equipment utilized, and distance traveled from mines to handling plant, and approximate the energy utilization and emissions anticipated. The components in the Lithium work flow chart will be represented by a progression of calculations in the worksheets, and individual cells in the worksheets will be utilized to give assumptions and data values required by the estimations. At each step in the flow chart inside the worksheets, client input factors decide output parameters that proceeds into the following system component. A user interface page will enable the client to determine the procedures that will be utilized and different assumptions made in the model.

For instance, the client will have the option to use a drop-down menu to choose the areas at which Lithium will be mined and prepared and the sorts of mining and transportation that will be utilized in each progression. Whenever finished, the client will likewise have the capacity to basically work backwards through the procedure stream and spreadsheet estimations, by indicating the quantity of Li-ion batteries required. The assumptions inside every module will then give an estimate of the measure of metal to be quarried (in view of mineral richness, handling plant area, process type, process productivity, equipment required at each stage, and so on.) and the energy consumed at each step. Every module is connected to the next module by means of the transportation grid. This transportation grid is required to track fuel utilization, time, and cost of stream of lithium battery product parts as they travel step by step from quarry to definite disposal site. This model will be an open access display for anybody to utilize the information and presumptions can be enhanced with the time.

\subsection{Resource Withdrawal Module}

The main module, known as the 'Resource Withdrawal Module', comprises of procedures associated with extracting lithium through extraction or mining. Distinctive lithium work flows sub-components are accessible inside this module, depending on whether the lithium is acquired through physical or chemical procedures. Lithium is mostly found in brine solutions and hard rocks and in low sums in clay deposits. Brine sources are additionally named mainland, geothermal, and oilfields and enable clients to make a choice.

Table 2. Input and Output Quantities from Brine and Hard-Rock Process

\begin{tabular}{|c|c|c|}
\hline Process & Input & Output \\
\hline Brine & $\begin{array}{c}\text { Location, type of brine, type of equipment, } \\
\text { labor operating hours and wages, } \\
\text { equipment operating hours, fuel type, } \\
\text { electricity use and mix }\end{array}$ & $\begin{array}{c}\text { Water consumption, energy } \\
\text { consumption, labor and capital cost, } \\
\text { lithium chloride, lithium carbonate, } \\
\text { potash }\end{array}$ \\
\hline $\begin{array}{c}\text { Hard- } \\
\text { Rock }\end{array}$ & $\begin{array}{c}\text { Location, Type of mineral, type of } \\
\text { machinery, labor operating hours and } \\
\text { wages, machinery operating hours, fuel } \\
\text { type, electricity use and mix }\end{array}$ & $\begin{array}{c}\text { Water consumption, energy } \\
\text { consumption, labor and capital cost, } \\
\text { lithium concentrate, lithium hydroxide, } \\
\text { lithium carbonate, potash }\end{array}$ \\
\hline
\end{tabular}


The client will have the capacity to indicate the ore of the metal and the equipment engaged with mining and handling as model assumptions. [9] They will also have the alternative to choose from a drop down menu or specifically input quantitative information into relevant cells. For instance, area of the brine solution, sort of the brines, kind of equipment, fuel type, will be accessible as drop down menu parameters. Labor working hours, work cost, and equipment working hours will be estimated after the ore input. The yields will be in tons or $\mathrm{kg}$ of material created which can be utilized as a part of Training \& Development to model the transport of crude materials.

\subsection{Transportation Module}

Material distribution and handling will be represented under 'Transportation Mode System' segment which will be displayed with utilizing a GIS (Geographic Information System) and the GREET (Greenhouse gases, Regulated Emissions, and Energy use in Transportation) model. The model, created by Argonne National Lab will be valuable in evaluating air emanations and energy impacts for the duration of the life cycle of Lithium-ion batteries. GREET is isolated in two sections: GREET 1 arrangement assesses the fuel cycle from well to wheels and GREET 2 arrangement assesses the vehicle cycle including pump to wheels, vehicle disposition, and material retrieval.

GIS helps to map household rail and road layers to build up the transportation logistics to limit time and cost. A variety of installed transport chain choices will be accessible for clients to determine in the model inside every module. For instance, prepared metal can be moved by truck, truck-rail-truck, compartment ships, and so on. This segment of the model will be elaborate yet will give clients a lot of adaptability. GREET has a built in transportation and circulation module called Transmission-Distribution (T\&D) to represent transporting crude materials to and from the site. Trip distance, measure of material transported, and fuel type are indicated with respect to the method of transportation: truck, tanker, boat, and rail utilized in the procedure to decide the energy utilization (Btu/ton of material transported), energy intensity (Btu/ton-mile), total emissions (grams/ton of material transported) and urban emissions (grams/ton of material transported) by mode. Fuel cost and material transport costs are also represented in the process. The GREET T\&D displaying components will be utilized each time material is transported from one module to the next.

\subsection{Battery Production and Assembly Module}

In this module, all the material and segments required to shape a battery pack will be demonstrated. Lithium and its co-items are sent as inputs to the battery organizations which create cell materials and yields from those organizations will be contributions to cell manufacture and generation organizations. A battery pack is gathered from the outputs of creation and production organizations. This module will comprise a list of all the potential key organizations engaged with creating different parts of the battery. Organizations will be arranged on the basis of their skill in building up a battery segment and will be arranged into classifications. Clients will have the capacity to choose the key battery players and their area to process for transportation vitality utilize and cost.

The GREET 2 model can be utilized to evaluate energy utilization and emanations for battery material preparing and creation, where clients can include percent share of key material structure in particular liquids, and share of electricity utilize and mix in the generation of battery materials. [10] Assembled battery packs are sent as inputs to the vehicle manufacturing process in the following module, delivering vehicles as outputs for 
buyers. Energy consumption, cost, and emanations from transporting items to installing plant is displayed utilizing T\&D and can be found in Table 3.

Table 3. Input and Output Quantities from Battery Manufacturing Module

\begin{tabular}{|c|c|c|}
\hline Process & Input & Output \\
\hline Battery & $\bullet$ Lithium compounds & $\bullet$ Cell material \\
manufacturing & $\bullet$ Cell material & $\bullet$ Battery pack \\
& $\bullet$ Key players, electricity use and \\
& mix, battery material \\
& composition & $\bullet \begin{array}{c}\text { Energ consumption at plant and } \\
\text { transport of materials, cost, } \\
\text { water use }\end{array}$ \\
\hline
\end{tabular}

Lithium Compounds (in tons or $\mathrm{kg}$ ) got from the 'Resource Withdrawal Module' will go as input to this module alongside other battery material for creation of cell material and number of cells required to make a battery pack will be the input to estimate the battery pack production.

\subsection{Vehicle Manufacturing Module}

In this module, GREET 2 is utilized to approximate energy use from vehicle generation and vehicle assembly. Material production and composition should be distinguished and are given in GREET. Clients can alter and input composition of material utilized as a part of vehicle production, weight of the materials, weight of the vehicle, battery specific power, and power utilized at installation plant and working productivity of the plant. Produced vehicles are sent to distribution center or yard stockpiling until the point that they are prepared to be sold at dealership. This component will again be displayed again utilizing T\&D. Extra vitality utilization and cost related with capacity of parts at the stockroom versus at the dealership will be represented by means of power utilize and power blend.

Energy consumption related with the delivery of vehicles to dealerships by means of cargo or auto transporter trailers will likewise be demonstrated utilizing T\&D in GREET. At the point when the vehicle reach the dealership, energy consumption and cost will likewise modelled for time spent at dealership, until bought by customers (refer Table 4).

Table 4. Input and Output Quantities from Vehicle Manufacturing Module

\begin{tabular}{|c|c|c|}
\hline Process & Input & Output \\
\hline Installation & $\begin{array}{c}\text { Vehicle material composition, material weight, battery } \\
\text { weight, battery specific power and energy, electricity } \\
\text { use and mix, plant operating efficiency }\end{array}$ & Energy use \\
\hline Storage & Electricity use and mix, maintenance & Energy consumption, cost, \\
\hline Delivery & $\begin{array}{c}\text { Actual vehicle cost, additional subsidies/benefits, time } \\
\text { spent at dealership }\end{array}$ & $\begin{array}{c}\text { Energy consumption, cost } \\
\text { of not being sold }\end{array}$ \\
\hline
\end{tabular}




\subsection{Consumer Module}

The battery being used will be demonstrated in fourth module, known as 'Consumer Module'. Vehicles transported from dealership to buyer will create discharges and consume energy; subsequently, T\&D parameter will be utilized to estimate those figures. Clients will have the choice to include the number of buyers that vehicle was passed along to in its lifetime, beginning from the first owner of the auto as 'purchaser 1', to the second customer, and so on to consumer $n$; where $n$ refers to the aggregate number of buyers in the lifetime of the vehicle. The model will be prepared to figure the depreciated value of the original vehicle as it go down and repaired all through vehicle's useful life, in view of the final cost of the vehicle estimated after modelling mishaps, harms caused, battery repair and replacement costs, and other servicing costs, all of which originates from client input. The estimated final value of the battery, and in addition the vehicle, will be compared with the original cost of both to assess and break down the general monetary profit or loss the vehicle had subjected to in its lifetime. Emissions can likewise be computed based on the miles traveled, proficiency of the battery, lifetime of the battery, and fuel intake. Information and output from this module are appeared as in Table 5.

Table 5. Input and Output Quantities from Consumer Module

\begin{tabular}{|c|c|c|}
\hline Process & Input & Output \\
\hline In-Use & $\begin{array}{c}\text { Number of consumers, vehicles per mile travelled, battery } \\
\text { efficiency, lifetime of the battery, fuel intake, number of } \\
\text { vehicle accidents, vehicle and battery repairs maintenance }\end{array}$ & $\begin{array}{c}\text { Cost of the car after use, } \\
\text { energy consumption, in- } \\
\text { use emissions }\end{array}$ \\
\hline
\end{tabular}

\subsection{End of Life Module}

The end of life of the batteries when they are never again being used is displayed in fifth module as 'End of Life Module'. Vehicles after their valuable lives are sent to junkyard where they are either sent to landfill, third party reusing or to waste site and have related transportation cost, discharges, and energy utilization from T\&D in GREET.

Table 6. Input and Output Quantities from End of Life Module

\begin{tabular}{|c|c|c|}
\hline Process & Input & Output \\
\hline Landfill & $\begin{array}{l}\text { Number of batteries in landfill, } \\
\text { pollutant type and quantity }\end{array}$ & Energy use, Emissions, Cost \\
\hline Recycling & $\begin{array}{l}\text { Reused and recovered material } \\
\text { composition, material's second life, } \\
\text { electricity use and mix at plant }\end{array}$ & $\begin{array}{l}\text { Price of recycled/recovered material, } \\
\text { recycling efficiency, type and quantity of } \\
\text { recycled material, energy intensity and } \\
\text { use, water use }\end{array}$ \\
\hline $\begin{array}{l}\text { Hazardous } \\
\text { waste site }\end{array}$ & $\begin{array}{l}\text { Pollutant type, concentration of } \\
\text { pollutants }\end{array}$ & $\begin{array}{l}\text { Emissions, Environmental and Human } \\
\text { health impact }\end{array}$ \\
\hline
\end{tabular}

When all the inputs are entered into the model, outputs gives add up of total energy and material utilization from extraction to disposition of Lithium-ion batteries. Clients will have the capability to inspect the practicality of different process components and investigate 
approaches to limit the effect of the outputs. The input and output parameters from end-oflife module are as given in Table 6. The proposed lifecycle will help policymakers in understanding the material supply and demand and to survey the practicality of reusing and improvement of regulations related with Lithium-particle battery innovation.

\section{Conclusions}

Lithium-ion batteries are turning into a prevailing battery science to control the transportation sector due to their technical characteristics and their application in electric and hybrid vehicles. As these batteries turn out to be more encouraging with passing time and elaborate research, the long term accessibility of lithium utilized as a part of assembling of Li-ion batteries may turn into a source of concern. Different government and industry specialists have guaranteed huge stores of lithium all around all with varied reporting. The disparity in the information and absence of precision in revealed information is probably going to cause supply demand imperatives later on and hamper the advancement of this technology.

The Lithium work flow chart tracks the flow of lithium from extraction, to battery production, to end of life. When combined with estimates of Li-ion battery demands, the model will be valuable in surveying whether there is sufficient lithium to control the future worldwide demand and when it is important to execute Li-particle battery reusing.

Despite the fact that Li-ion batteries are an exceptionally promising innovation, the specialists should concentrate on battery production, as well as on the fate of these batteries toward the end of life. Reusing battery materials and segments may lessen weight on natural resources by requiring the extraction of less virgin material, diminishing assembling costs by incorporating reused materials, and decreasing general energy consumption related with creation. Thus, this model could demonstrate helpful as an instrument for policymakers to implement and deal with the recycling foundation.

\section{References}

1. Budde-Meiwes, H., Drillkens, J., Lunz, B., Muennix, J., Rothgang, S., Kowal, J., Uwe Sauer, D. (2013), "A review of Current automotive battery technology and future prospects.", Journal of Automobile Engineering. 227: 761. http://pid.sagepub.com/content/227/5/761.full.pdf+html

2. Navigant Research. (2014). "Electric Vehicle Batteries: Lithium Ion Batteries for Hybrid, Plug-In Hybrid, and Battery Electric Light Duty Vehicles, Market Analysis and Forecasts". http://www.navigantresearch.com/research/electric-vehicle-batteries.

3. USGS (2014) "Lithium.” US Geological Survey, Mineral Commodities Summaries. http://minerals.usgs.gov/minerals/pubs/commodity/lithium/mcs-2014-lithi.pdf.

4. Gaines, Linda and Nelson, Paul. (2009). "Lithium-Ion Batteries: Possible Materials Issue.”, Argonne National Lab. http://www.transportation.anl.gov/pdfs/B/583.pdf.

5. MIT Electric Vehicle Team. (2008). "A Guide to Understanding Battery Specifications.", Massachusetts Institute of Technology, http://web.mit.edu/evt/summary_battery_specifications.pdf

6. Pesaran, Ahmad \& Markel, Tony. (2007), "Battery Requirements and Analysis for Plug-In Hybrid Vehicles.", National Renewable Energy Laboratory. http://www.nrel.gov/vehiclesandfuels/energystorage/pdfs/42082.pdf

7. Lowe, M., Tokuoka, S., Trigg, T., Gereffi, G. (2010). "Lithium-Ion Batteries for Electric Vehicles: The US Chain.", 
https://unstats.un.org/unsd/trade/s_geneva2011/refdocs/RDs/LithiumIon\%20Batteries $\% 20($ Gereffi\%20-\%20May\%202010).pdf

8. Ford Sustainability Report. (2010). "Ford's Electrification Strategy". Ford. http://corporate.ford.com/doc/sr10.pdf

9. Mohr, M., Mudd, G., Guirco, D. (2012). "Lithium Resources and Productions: Critical Assessment and Global Projections." Minerals. http://www.mdpi.com/2075$163 \mathrm{x} / 2 / 1 / 65 / \mathrm{pdf}$

10. Burnham, A., Wang, M., Wu, Y. (2006). "Development and Application of GREET 2.7 - The Transportation Vehicle-Cycle Model" 